\title{
ALBACETE (1924-1936)
}

\section{Emilia Ochando Madrigal}

\section{PANORAMA GENERAL BREVE DEL TEATRO ESPAÑOL.}

Entre los años de 1890 y 1915, aproximadamente, los géneros literarios presentan multiplicidad de formas, encaminadas unas a la innovación y otras a la pervivencia de los géneros heredados del siglo anterior, aunque con leves actualizaciones. El teatro sufre una serie de transformaciones que hacen cambiar el aspecto de los géneros dramáticos tradicionales: el sainete, el drama rural y la alta comedia; el primero evoluciona hacia el teatro cómico (con el astracán y la tragedia grotesca) y los dos últimos adquieren mayor dignidad literaria. Junto a ellos perviven el drama poético en verso - expresión del Modernismo más estetizante- y los intentos renovadores de ValleInclán (cuyo teatro adquiere la libertad de la novela) y de Unamuno (que plantea en sus tragedias los mismos problemas metafísicos de sus ensayos).

Junto a las fórmulas populares del llamado «género chico», aparece otro tipo de teatro - artificioso, efectista y de corte neorromántico- 
encarnado en la pluma de José Echegaray; este autor dominó la escena española durante el último cuarto del siglo XIX, y aún bien entrado el siglo XX. La mayoría de los estudiosos del teatro decimonónico han sido muy críticos con el teatro de Echegaray; así, Ruiz Ramón (1986:350) lo denomina «drama-ripio» en cualquiera de sus niveles (vocabulario, sentimiento, acción, etc.) y considera que representa un mundo falso y gesticulante, lleno de tópicos. A pesar de ello, el dramaturgo tuvo una pléyade de continuadores, que llenaron la escena española en el primer tercio del siglo: Leopoldo Cano, Eugenio Sellés, Felíu y Codina, etc.

Al margen del teatro comercial, otros dramaturgos renovaron la escena en este periodo, cada uno dentro de su propia ideología y de su peculiar modo de entender el teatro; son autores como Benito Pérez Galdós, Joaquín Dicenta o Ángel Guimerá. El esfuerzo innovador de éstos y otros escritores no llegó a cuajar hasta muchos años después, y el teatro europeo no consiguió tampoco aclimatarse en España. El teatro que triunfaba era aquel que prefería el público y que consagraba a sus autores; un teatro muy comercial, de fácil construcción e ideología ramplona: el teatro de los hermanos Álvarez Quintero, de Muñoz Seca, de Benavente, etc.

A partir de 1914, aproximadamente, comienza a hablarse de crisis del teatro; a éste le salen, por entonces, competidores tan feroces como el cinematógrafo y los espectáculos de variedades. A pesar de ello, la actividad teatral no decae y cada vez se construyen más edificios teatrales; el público acude en masa a los teatros y los empresarios obtienen pingües beneficios.

Empiezan a cobrar importancia, entonces, aspectos teatrales no tenidos muy en cuenta hasta la fecha: la dirección de escena, la decoración, ambientación, iluminación, vestuario, maquillaje, etc., así como nuevas técnicas de representación. El término teatro del arte es acuñado en los años veinte, designando experimentos escénicos que ya habían sido realizados en el extranjero. Destacan en este intento Gregorio Martínez Sierra con su «Teatro del Arte» y Cipriano de Rivas Cherif —discípulo de Gordon Craig en Italia- que intentó aplicar en España las teorías del «Teatro de Arte de Moscú»; creó el teatro de cámara El Cántaro Roto (dirigido por Valle-Inclán) y, después, el teatro de arte El Caracol, además de una escuela dramática (el TEA, Teatro Escuela de Arte) donde se impartían enseñanzas del arte escénico con técnicas europeas. También realizaron experimentos escénicos algunos grupos de teatro, como La Barraca (formado por estu- 
diantes madrileños y dirigido por García Lorca y Ugarte), El Búho (dirigido por Max Aub), o el Club Teatral Anfistora (creado por Pura Ucelay). También es importante destacar el trabajo de una de las más singulares creaciones oficiales de la época republicana: las «Misiones Pedagógicas», formada por estudiantes y profesores universitarios que, desde el verano de 1933, recorrían las zonas rurales del país para - además de otras actividades - llevar las obras de nuestro teatro clásico, dirigidos por el dramaturgo Alejandro Casona. El trabajo de estos grupos se desarrollará fundamentalmente en los años treinta. Otro intento de renovar la escena española se produce al final del periodo: cuando llega al poder el Frente Popular (1935), Max Aub presenta al gobierno un plan para fundar un teatro nacional, la creación de teatros experimentales, así como la reforma del conservatorio y la creación de una escuela nacional de baile; estos proyectos no podrán llevarse a cabo por el comienzo de la contienda civil.

Mientras tanto, y a pesar del esfuerzo de los grupos teatrales independientes y de algunos autores renovadores de la escena (como Rafael Alberti, Pérez de Ayala, Casona y los anteriormente mencionados), el panorama teatral en los años de la República continúa siendo un reducto del conservadurismo estético y moral: sigue triunfando la comedia ligera e intranscendente de los Álvarez Quintero, la alta comedia de Benavente, Linares Rivas, Martínez Sierra o Felipe Sassone (y los continuadores de éstos, Pilar Millán Astray, Enrique Suárez de Deza, Antonio Paso, etc.), y la astracanada de Muñoz Seca, el cual se inclinó —en los últimos años- hacia la comedia de tesis política; otro autor que apuntaba en la misma dirección era José María Pemán, con sus poemas dramáticos de ideología tradicionalista.

En cuanto al teatro lírico, junto a las formas heredadas de la época anterior (zarzuela, sainete, ópera, género chico, etc.) que intentan recuperarse y lograr mayor entidad musical, estos años conocen el resurgimiento de la revista musical que, junto con otras derivaciones del «género ínfimo» (como las variedades, el cuplé, el género sicalíptico, etc.) llenará las salas de espectáculos reemplazando, en gran medida, a los géneros tradicionales. Todos ellos en franca competencia con el cinematógrafo.

Los escritores vanguardistas se interesaron pronto por lo que este nuevo arte tenía de espectáculo total y por la atracción que ejercía sobre las masas. Durante los primeros años las producciones eran extranjeras, pero pronto aparecieron películas españolas, la mayoría basadas en obras teatrales de gran éxito (La casa de la Troya, Currito 
de la Cruz, etc.) que aprovecharon la popularidad de las actrices y cupletistas de moda; se crearon empresas nacionales de distribución y producción (Filmófono, Cifesa), que se orientaron hacia la comedia ligera, la zarzuela y las obras que representaban un folclorismo estereotipado del arte popular español. Estas producciones continuaron realizándose y proyectándose con gran éxito después de la guerra civil.

\section{EL TEATRO EN ALBACETE}

Lo que ocurre en los escenarios albaceteños en los años veinte y treinta se puede extrapolar a otras provincias españolas y es, en pequeña escala, un trasunto de lo que está sucediendo en la vida escénica de la capital, Madrid.

Las representaciones teatrales son muy numerosas en la ciudad de Albacete. Por ella pasan las compañías más famosas del momento: la de María Guerrero, la de Margarita Xirgu, la de Paco Fuentes, la de María Palou, la de Ricardo Calvo, etc. También llegan a la ciudad compañías de aficionados que recorren el país con sus representaciones, como la de las «Misiones Pedagógicas» o la del grupo universitario La Barraca, dirigida por García Lorca. Las obras más llevadas a escena son las del género cómico, en sus múltiples variedades; se dan con mayor frecuencia representaciones de teatro declamado que de teatro lírico, aunque son muchas las compañías de zarzuela que visitan Albacete en estos años (la del maestro Serrano o la del maestro Guerrero, entre las más famosas).

Junto al teatro tradicional, dos nuevos espectáculos compiten con aquél por atraer al público: son el cinematógrafo y los espectáculos de variedades (cuplés, bailes, imitaciones, transformismo, revista musical, etc.). Los locales donde tradicionalmente se representaban obras de teatro, abren sus puertas para acoger estas nuevas formas de diversión, que el público demanda cada vez con más interés; además, se crean otros locales nuevos dedicados íntegramente a estos géneros.

Por otra parte, la actividad teatral de los casinos y sociedades culturales en Albacete es también intensa en estos años: no hay sociedad que se precie que no tenga su propio cuadro artístico, formado por socios aficionados al teatro; éstos suelen realizar veladas teatrales con cierta frecuencia, casi siempre orientadas a recabar dinero para fines benéfi- 
cos. No obstante, la proliferación de estos grupos teatrales nos aproxima más a la convicción del gran interés que por el teatro tenían los ciudadanos albaceteños, de las clases cultas, en el primer tercio de siglo.

En síntesis, el panorama cultural y artístico que presenta la ciudad de Albacete en los primeros años del siglo XX muestra un alto índice de actividad cultural en todos los órdenes, pese a la escasez de medios y de lugares adecuados para la realización de espectáculos. Conforme avanza el siglo, estas deficiencias se van paliando, merced al esfuerzo de un grupo de albaceteños de las clases cultas dirigentes de la ciudad, los cuales se dedican a construir nuevas salas de espectáculo, a traer las mejores compañías profesionales que actúan en España, a organizar grupos de actores, a escribir obras de teatro y a representarlas. Por otro lado, el cinematógrafo y las variedades comienzan a imponerse sobre otras formas de espectáculo - condicionando un cambio en los gustos del público hacia un tipo de espectáculo más variado, intranscendente y dinámico- y provocan la llamada «crisis teatral», en la que influyen también cuestiones de orden económico y literario, y que afecta por igual a todo el país.

Las compañías que actúan en los teatros albaceteños durante los años que van de 1924 a 1936 son 150 , de las cuales 135 son distintas (es decir, el propietario - primer actor - y la mayoría de los actores son diferentes en cada una). De ellas son compañías profesionales 118 y están formadas por actores aficionados 17 . Entre las compañías profesionales existen cinco extranjeras (dos mexicanas, dos argentinas y una americana), todas ellas de habla hispana; el resto (115) son españolas.

De estas compañías, se dedican a representar los géneros declamados 75 y las otras 43 a los géneros líricos. Dentro de las primeras, la mayoría son cómicas (50), algunas son dramáticas (12) y otras combinan ambas modalidades (13). Entre las primeras hay también algunas que se dedican a géneros nuevos, como la Compañía Rambal de Obras de Gran Espectáculo o la Compañía de Cinema-Teatro de Felipe Fernansuar. En cuanto a las segundas, 29 se dedican a la zarzuela y la opereta, 13 a la revista musical y las variedades y sólo una combina la zarzuela con la revista; también las hay dedicadas a géneros nuevos, como la Compañía de Comedias líricas flamencas Alcoriza.

Las compañías profesionales que más veces visitan Albacete en estos años son: la Compañía Dramática Guerrero-Díaz de Mendoza (6), la Compañía de Zarzuela del Maestro Serrano, la Compañía de 
Revista de Eulogio Velasco y la Compañía de Comedias BarrónGalache (5 veces cada una), y la Compañía Dramática de Margarita Xirgu (4 veces). Sin embargo, la mayoría de ellas (91) sólo actúan en una ocasión en la ciudad. La duración de sus estancias varía considerablemente entre uno y varios días, según el número de obras que representen; la compañía que mayor número de representaciones realiza en la ciudad es la Compañía de Revistas del Teatro Ruzafa de Valencia (50).

Todas estas compañías están formadas básicamente por una figura de la escena (primer actor o primera actriz), que suele ser a la vez empresario, director y protagonista de las obras que la compañía representa; a veces, estas funciones se reparten entre varias personas. El repertorio de obras de cada compañía también suele ser muy extenso, y casi siempre está hecho a medida de las dotes interpretativas del primer actor o primera actriz. El número de actores que cada compañía lleva es variado, aunque gira alrededor de veinticinco personas; las compañías líricas exceden dicho número, destacando la Compañía de Zarzuela y Revista Gómez Gimeno con cincuenta y ocho actores, además del equipo técnico. La mayoría de los actores van pasando de unas compañías a otras, y éstas se renombran según su director y primer actor (Gatuellas/Iglesias-Gatuellas, Soler Mary/Soler Mary-Rodríguez de la $V e g a$, etc.) o según los géneros que representen (por ejemplo, la compañía de Amalio Alcoriza se denomina sucesivamente de dramas policiacos, de obras de gran espectáculo, de comedias líricas flamencas).

Además de los actores, cada compañía lleva su propio equipo técnico, formado por escenógrafos, pintores, sastres, electricistas, etc. que se encargan del montaje de las obras y el atrezzo. Conforme avanza el siglo, observamos mayor interés por parte de las compañías en cuidar los aspectos de la escenografía, sobre todo cuando se trata de realizar obras «de gran espectáculo» que necesitan montajes muy complicados, pero que cautivan la atención del espectador; es - sin duda - un intento por acercar el teatro al espectáculo cinematográfico.

Además del director de escena, aparece en muchas compañías la figura del director artístico o asesor literario, que cuida los aspectos relacionados con el texto dramático; $\mathrm{y}$, a veces, también encontramos otras figuras como el regidor de escena, el maestro concertador (en obras líricas), etc.

En cuanto a las compañías de actores aficionados, la mayor parte (13) son de Albacete y se forman en las sociedades culturales de la ciu- 
dad (los cuadros artísticos del Ateneo de Albacete, del Círculo de Bellas Artes, del Casino Artístico, etc.) y suelen actuar en festivales organizados para recaudar fondos con fines benéficos. Las cuatro restantes pertenecen a grupos de aficionados procedentes de otras localidades, destacando entre ellas el grupo de las Misiones Pedagógicas, dirigido por Alejandro Casona, y el grupo universitario La Barraca, dirigido por García Lorca y Ugarte; ambos recorren España llevando las principales obras del teatro clásico a pueblos y ciudades del país, realizando sendas representaciones en Albacete en 1933.

Las compañías antes mencionadas, tanto profesionales como aficionadas, efectúan un total de 1.277 funciones en Albacete entre 1924 y 1936, con una media de 100 funciones por año, aproximadamente; los años que registran una mayor actividad teatral son 1928 (con 139 funciones) y 1929 (con 146 funciones). Los meses en que se concentra el mayor número de funciones son: septiembre (215), debido a la fiesta más importante que se celebra en la ciudad, la Feria, que comienza el día 7 y finaliza el 17; febrero (173) debido a las fiestas de Carnaval, también celebradas en la ciudad; diciembre y enero (151 funciones cada mes), meses en que se celebran las fiestas navideñas, época de descanso para la burguesía albaceteña. Los meses de menor intensidad teatral son julio (13) y agosto (14), temporada estival en que el público marchaba fuera de la ciudad y las compañías aprovechaban para descansar o para realizar sus giras españolas y americanas.

Algunas compañías realizaban estancias de varios días en la ciudad y realizaban funciones todos o casi todos los días; en algunos de ellos había dos o tres funciones; éstas solían ser una por la tarde (entre las 17.45 y 18.00 horas en invierno, y entre las 19.00 y las 19.30 horas en verano) y otra por la noche (entre las 21.45 y las 22.00 horas en invierno y entre las 22.15 y 22.30 horas en verano); el día de la semana preferido para celebrar dos funciones era el domingo, por ser éste festivo y tener mayor afluencia de público. A veces se celebraban sesiones en distintos horarios, como la «sección vermouth» (entre las 19.00 y 19.30 horas) y la sesión de madrugada (entre las 23.45 y 24.45 horas) en el Teatro Cervantes, durante los meses de verano.

Los precios de estas funciones variaban debido a múltiples causas: la compañía (las más caras eran la Guerrero-Díaz de Mendoza, la de Margarita Xirgu y la de Ricardo Calvo, entre las de teatro declamado, y las del maestro Serrano y la compañía Herrero-Pulido, entre las líricas; las más baratas, dejando aparte las de aficionados, eran la de María Klein y la lírica de Hilario Vidal); el tipo de función (solían ser 
más baratas el día del debut y el de la despedida); la hora de la función (más baratas por la tarde que por la noche) y el tipo de entrada (más barata por abono que a diario). Sin embargo, no se producía variación de unos teatros a otros. Los precios oscilaban por término medio entre las 24 pesetas de un palco (para cinco o seis personas) y las 0.70 pesetas de la entrada general, la más barata. Hay que señalar dos aspectos importantes en este punto: uno, que estos precios eran similares a los de otras ciudades importantes, como Madrid; otro, que los precios se mantienen más o menos estables durante todo el periodo estudiado, $\mathrm{e}$ incluso durante todo el primer tercio de siglo, debido — sin duda- a la necesidad de los empresarios por no encarecer las funciones teatrales ante la fuerte y desleal competencia de otros espectáculos que les van ganado terreno, esto es, las variedades y el cinematógrafo. Al problema que esto supone habría que añadir el de los impuestos que el Estado cobraba a los empresarios por las representaciones teatrales (además de los derechos de autor que reclamaba la Sociedad de Autores Españoles por las obras representadas), que oscilaban entre un 5 y un 15 por ciento sobre el precio de las entradas; por este motivo muchos empresarios teatrales se arruinaron, $y$ todos pedían menores gravámenes sobre sus empresas y subvenciones estatales para la actividad teatral. La crisis del teatro pasaba también por la crisis económica de las empresas teatrales.

Realizamos a continuación una descripción detallada del elenco que compone cada una de las compañías que más veces visitan Albacete en el periodo estudiado, mencionando las obras que representan en la ciudad y también las que incluyen en su repertorio de la temporada.

\section{COMPAÑíAS TEATRALES}

\subsection{Compañía Dramática Guerrero-Díaz de Mendoza} (12-5-25 a 14-5-25)

\section{A) Componentes:}

Alcántara, Francisca

Almarche, Joaquina

Alonso, Mariano 
Beringola, Juan

Bofill, Encarnación

Capilla, José

Climent, Remedios

Díaz de Mendoza, Fernando

Director y actor

Díaz de Mendoza y Guerrero, Carlos

Díaz de Mendoza y Guerrero, Fernando

Díaz Perchicot, Nicolás

Fernández, Concepción

Fernández, Félix

Férriz, Miguel Ángel

Guerrero, Ana

Guerrero, María

Primera actriz

Guerrero López, María

Iglesias, Manuela

Larrabeiti, Carmen

Martínez Tovar, Luis

Montojo, Fausto

Ortega, Ángel

Pino, Rosario

Taboada, Josefina

Vázquez, Juan

Yuste, Ricardo.

B) Repertorio de obras interpretadas:

Cancionera. Don Luis Mejía. Doña Perfecta.

Compañía Dramática Guerrero-Díaz de Mendoza (28-5-28 a 31-5-28)

\section{A) Componentes:}

Alcántara, Francisca

Algara, Gabriel

Almarche, Joaquina

Alonso, Mariano

Bofill, Encarnación

Capilla, José

Casterot, Carlos 
Climent, Remedios

Díaz de Mendoza, Fernando

Díaz de Mendoza Guerrero, Carlos

Díaz de Mendoza Guerrero, Fernando

Domínguez Luna, Manuel

González, Socorro

Guerrero López, María

Juste, Ricardo

Larra, Eduardo

Larra, María

Larrabeiti, Carmen

Márquez, Juan

Martínez Casado, Margot

Montojo, Fausto

Ortega, Ángel

Pino, Rosario

Sánchez, Elisa

Taboada, Josefina

Terry, Rafael.

B) Repertorio de obras interpretadas:

El demonio fue antes ángel. La mariposa que voló sobre el mar. ¡No quiero, no quiero! Sinrazón.

Compañía Dramática Guerrero-Díaz de Mendoza (25-12-29 a 1-1-30)

\section{A) Componentes:}

Alcántara, Paquita

Alonso, Mariano

Armengot, Luisa

Barroso, Irene

Bofill, Encarnación

Capilla, José

Climent, Remedios

Díaz de Mendoza, Fernando

Díaz de Mendoza Guerrero, Fernando

Fábregas, Emilio 
Fernández de Córdoba, Fernando

González, Socorro

Guerrero, María

Juste, Ricardo

Mesejo, Emilio

Montojo, Fausto

Morano, Fifí

Ortega, Ángel

Pino, Rosario

Sala, Fernando

Taboada, Josefina

Thuillier, Emilio

Valentín, María.

B) Repertorio de obras interpretadas:

Ella o el diablo. Entre desconocidos. La estrella de Sevilla. Las hogueras de San Juan. ¡No quiero, no quiero! Rondalla. La vida es más.

C) Otras obras del repertorio:

El demonio fue antes ángel. En Flandes se ha puesto el sol. Mancha que limpia. La mariposa que voló sobre el mar. Peleles. Sin horca ni cuchillo. El vergonzoso en palacio.

Compañía Dramática Guerrero-Díaz de Mendoza (19-4-30 a 22-4-30)

\section{A) Componentes:}

Armayor, Luisa

Contreras, Alberto (hijo)

Díaz de Mendoza, Fernando

Díaz de Mendoza Guerrero, Fernando

Fábregas, Emilio

Guerrero, María

Juste, Ricardo

Montojo, Fausto

Navarro, José María 
Pelayo, Enrique

Sala, Fernando

Taboada, Josefina

Tapias, Josefina

Vargas, Ricardo.

B) Repertorio de obras interpretadas:

El ladrón. Las mocedades del Cid. Sancho Avendaño. Los tres mosqueteros.

Compañía Dramática Guerrero-Díaz de Mendoza (14-2-31 a 18-2-31)

\section{A) Componentes:}

Adamuz, Ana

Almarche, Joaquina

Alonso, Mariano

Armayor, Luisa

Benedito, Adolfo

Beringola, Juan

Bofill, Encarnación

Capilla, José

Climent, Remedios

Criado, Társila

Díaz de Mendoza y Guerrero, Fernando

Dicenta, Manuel

Dolarea, Ángel

Fuentes, Francisco

García Ortega, Margarita

García Ortega, Rosario

Guerrero, María

Juste, Ricardo

Montojo, Fausto

Nestosa, Josefina

Osete, Enrique

Sala, Fernando

Taboada, Josefina

Valentín, María. 
B) Repertorio de obras interpretadas:

El abanico de Lady Windermere. El caudal de los hijos. Una conquista difícil. La niña boba o Buen maestro es amor. El perro del hortelano. La plancha de la marquesa. La ráfaga.

\section{Compañía Dramática Guerrero-Díaz de Mendoza}

(9-1-36 a 11-1-36)

\section{A) Componentes:}
Alcaide, Luis
Alcántara, Paquita
Armayor, Luisa
Benedicto, Alonso
Capilla, José
Carrillo de Albornoz, Luz
Díaz de Mendoza, Carlos
Díaz de Mendoza, Fernando
Dorado, José
García Ortega, Rosario
Grifell, Amparo
Grifell, Prudencia
Guerrero, María
Nestosa, Josefina
Ortega, Margarita
Pliego-Valdés, Alejandro
Ramírez, Ricardo
Sala, Fernando
Valle, Marta.

Primera actriz

Primer actor y director

B) Repertorio de obras interpretadas:

La dama de armiño. En Flandes se ha puesto el sol. Locura de amor. Mariquilla Terremoto. Pluma en el viento.

\section{C) Otras obras del repertorio:}

Doña María la Brava. La enemiga. El genio alegre. El gran Galeoto. La malquerida. Mancha que limpia. La mujer guapa. La niña boba. 


\subsection{Gran Compañía de Zarzuela del Maestro Serrano} (20-11-29 a 24-11-29)

\section{A) Componentes:}

Alarcón, Amparo Avelli, Trini Bofill, Celia Bray, Emilio Carrera, María Company, Miguel Cruz, Alfredo

Delgado, Juanita

Dotti, Carlos

Elvira, Lorenza

Ertogs, Pablo

Escrivá, Elisa

Fernández, Anselmo

García, Anita

García, Miguel

García, Pablo

Garrido, Antonio

González, Antonio

González, María Teresa

Gonzalo, Augusto

Jiménez, José

López, Alberto

Mariscal, Florencio

Martín, Francisco

Martínez, Antonio

Mas, Teresa

Mitret, Alfredo

Navarro, José

Palos, Francisco

Pérez, Lola

Peris, Clotilde

Ponsetti, Bernardino

Quesada, Manolita

Romero, Antonia

Romo, Amparo

Serrador, Antonio
Tiple

Tiple cómica

Segunda tiple

Maestro director y concertador

Segunda tiple

Actor

Barítono

Segunda tiple

Actor

Segunda tiple

Barítono

Segunda tiple

Primer actor y director

Segunda tiple

Actor

Actor

Tenor cómico

Actor

Segunda tiple

Tenor

Actor

Primer actor

Actor

Actor

Actor

Segunda tiple

Actor

Apuntador

Maestro director y concertador

Segunda tiple

Segunda tiple

Actor

Segunda tiple

Segunda tiple

Tiple

Apuntador 
Vendrell, Emilio

Villar, Francisco

Zaldívar, María

Armería: Gutiérrez

Decorados: Valera y Zabala

Gerente: Campa, Aurelio

Maquinista: Puig, Jaime

Peluquería: Beltrán, Teodoro

Representante: Bofill, Pablo G.

Sastrería: Peris Hermanos

Zapatería: López Arbós.
Tenor

Actor

Característica

B) Repertorio de obras interpretadas:

La alegría del batallón. Los claveles. Los de Aragón. Gente seria. Las hilanderas. El mal de amores. La reina mora.

\section{Gran Compañía de Zarzuela del Maestro Serrano}

(21-11-30 a 23-11-30)

\section{A) Componentes:}

Ambit, Gonzalo

Andújar, Antonio

Balduque, Sergio

Domínguez, Luis

Ferrer, Ismael

Gabarri, Jerónimo

Garrigós, Salvador

Grajales, Ernesto

Iniesta, José

Latorre, José

López, Encarnación

López, Rafael

López, Sara

Llopis, Salvador

Martí, Vicenta

Mauri, Mercedes

Mauri, Vicente

Moreno, Luis
Tenor cómico

Actor

Apuntador

Actor

Apuntador

Barítono

Actor

Tenor cómico

Actor

Tenor

Primera tiple

Maestro director y concertador

Actriz de carácter

Actor

Primera bailarina

Actriz de carácter

Primer actor

Barítono 
Raga, Cora

Ruiz Paris, Valeriano

Sempere, Vicente

Soriano, Francisco

Stern, Concha

Tayana, Aurelio

Zaragoza, José

Quince coros y conjunto de baile.
Primera tiple

Primer actor

Tenor

Maestro director y concertador

Primera tiple

Actor

Tenor

\section{B) Repertorio de obras interpretadas:}

Alma de Dios. La casita blanca. Los claveles. La Dolorosa. La reina mora.

C) Otras obras del repertorio:

Doloretes. Las hilanderas. Los de Aragón. Moros y cristianos. El Motete. El olivar. El solo de trompa. Suerte loca. La venda en los ojos.

\section{Compañía de Zarzuela y Ópera Española del Maestro Serrano (27-10-32 a 30-10-32)}

\section{A) Componentes:}
Alós, Vicente
Amorós, Concha
Benítez, Daniel
Campos, José
Gabarri, Gerónimo
García, Maruja
Genovés, Genaro
Latorre, Antonio
López, Alberto
López, Encarna
López, Rafael
López, Sara
Martínez, Amparo
Navarro, Emilio
Oriendo, Eloy
Ponce, Jorge

Actor

Tiple

Tenor cómico

Tenor cómico

Barítono

Tiple

Apuntador

Primer tenor

Actor

Primera tiple cómica

Maestro director y concertador

Actriz de carácter

Tiple ligera

Actor

Barítono

Primer tenor 
Ponce, Margarita

Puerto, Vicente

Raga, Cora

Ruiz Paris, Valeriano

Sánchez, Juan

Sempere, Vicente

Serrano, José

Soriano, Francisco

Zaragoza, Antonio
Tiple dramática

Actor

Tiple dramática

Primer actor y director

Actor

Divo tenor

Director artístico

Maestro director y concertador Actor

Coro de caballeros y segundas tiples

Archivo: Sociedad de Autores Españoles

Decorado: propiedad de la Empresa

Empresa: Campa-Alarcón

Maquinista: Ibáñez, Francisco

Peluquería: Lita, Vicente

Sastrería: Viuda de Ramón Peris.

\section{B) Repertorio de obras interpretadas:}

Al dorarse las espigas. La canción del olvido. Los claveles. La Dolorosa. Katiuska. Los de Aragón.

Gran Compañía de Zarzuela del Maestro Serrano (30-8-33)

\section{A) Componentes:}

Andújar, José

Conti, Enriqueta

Corro, Carmen

Fernández, Anselmo

Fleta, Miguel

Genovés, Genaro

Molina, Manuel

Moreno, Luis

Puerto, Vicente

Revenga, Matilde

Riera, Amadeo
Actor genérico

Primera tiple cómica

Actriz de carácter

Primer actor y director

Primer tenor

Apuntador

Actor cómico

Primer barítono

Apuntador

Primera tiple

Maestro director y concertador 
Sánchez, Juan

Ventura, Rigoberto

Coro general.

B) Repertorio de obras interpretadas:

La Dolorosa.

\subsection{Compañía de Revistas de Gran Espectáculo de Eulogio} Velasco (6-2-32 a 9-2-32)

\section{A) Componentes:}

Abeytúa, José

Andrés, Carmen

Arcos, Rafael

Benlloch, Julián

Bilbao, Julia

Butier, Francisco

Caballé, Emilia

Caballé, María

Gallego, Rafael

Gimeno, Joaquín

Moriña, Alfredo

Navalón, Angelita

Navarro, Luis

Oltra, Francisco

Palomera, José

Pardo, Constantino

Paso, Mercedes

Perales, Pilar

Ruiz, Francisco

Suárez, Cándida

Taberner, Amparo

Triana, Toni

Velasco, Eulogio

Verdiales, Julia
Actor de carácter

Maestro director y concertador 
Treinta vicetiples

Decorados: Asensi, Burmann, Morales y Redondela.

Gerente representante: Gantes, Daniel

Vestuario: Estellés (Madrid), Max Weldy (París) y Pepita (Barcelona).

B) Repertorio de obras interpretadas:

Cocktail de amor. Flores de lujo. La musa gitana. Noche de cabaret.

Compañía de Revistas de Gran Espectáculo de Eulogio Velasco (12-5-33 a 14-5-33)

A) Componentes:

Benlloch, Julián Maestro director y concertador

Bilbao, Julia

Butier, Francisco

Caballé, María

Escrivá, Elena

Escrivá, Félix

Estrada, Adela

Gimeno, Joaquín

López Martínez, María

Moriña, Alfredo

Navalón, Angelita

Navarro, Luis

Maestro director y concertador

Oltra, Francisco

Palomares, José

Pernaz, Eduardo

Sáiz, Aurora

Triana, Tony

Bailarín

Velasco, Eulogio

Director

Verdiales, Julia

Treinta vicetiples.

B) Repertorio de obras interpretadas:

Bellezas del mundo. Cocktail de amor. Las Leandras. 
Compañía de Revistas de Gran Espectáculo de Eulogio Velasco (10-9-34 a 17-9-34)

A) Componentes:

$\begin{array}{ll}\text { Alares, Rafael } & \text { Primer tenor cómico } \\ \text { Arquelladas, Manuel } & \text { Maestro director y concertador } \\ \text { Bori, Luis } & \text { Primer actor } \\ \text { Fuentes, Francisco } & \text { Maestro director y concertador } \\ \text { Galindo, Alda } & \text { Tiple } \\ \text { Guillén, Alfredo } & \text { Tenor cómico } \\ \text { Gutiérrez, Antonio } & \text { Actor } \\ \text { Lacalle, Anita } & \text { Primera tiple } \\ \text { Lacalle, María } & \text { Primera tiple } \\ \text { Leonardo, Conchita de } & \text { Primera vedette } \\ \text { Lorente, Julio } & \text { Actor } \\ \text { Martínez, Charito } & \text { Tiple } \\ \text { Moriña, Alfredo } & \text { Actor } \\ \text { Navalón, Angelita } & \text { Primera tiple } \\ \text { Parra, Enrique } & \text { Primer actor } \\ \text { Pitcher } & \text { Primer bailarín } \\ \text { Ubago, Carmen } & \text { Tiple } \\ \text { Veinticinco vicetiples. } & \end{array}$

B) Repertorio de obras interpretadas:

La camisa de la Pompadour. Las insaciables. Las peponas. Las tentaciones.

Compañía de Revistas de Gran Espectáculo de Eulogio Velasco (24-11-34 a 26-11-34)

\section{A) Componentes:}

Bernal, sr.

Bori, Luis

Primer actor

Farry Sisters

Pareja de baile

Guillén, Alfredo

Tenor cómico

Lasalle, Anita

Tiple cómica 
Lorente, Julio

Navalón, Angelita

Páez, Conchita
Actor

Primera tiple

Supervedette.

B) Repertorio de obras interpretadas:

La camisa de la Pompadour. Las insaciables. Las tentaciones.

Compañía de Revistas de Gran Espectáculo de Eulogio Velasco (25-12-34 a 29-12-34)
A) Componentes:

Bori, Luis

Escribá, sta.

Farry Sisters

Guillén, Alfredo

López Martínez, sra.

Lorente, Julio

Martínez, Charito

Navalón, Angelita

Páez, Conchita

Vega, Jacinta de la

Vicent, sta.
Primer actor

Pareja de baile

Tenor cómico

Actor

Tiple cómica

Primera vedette

B) Repertorio de obras interpretadas:

Las corsarias. La camisa de la Pompadour. Las de Villadiego. Las tentaciones.

3.4. Compañía de Comedias de Isabel Barrón (31-1-31 a 9-2-31)
A) Componentes:

Acevedo, Rafael

Albaladejo, Amalia

Alcalde, María

Arcal, Manuel 
Barrón, Isabel

Delor, Trini

Derby, Mary

Esquembre, José

García Guerrero, Luis

Guerrero, María

Jerez, Delfín

Larrabeiti, Mariana

Mas, Herminia

Martín, María

Moya, Vicente

Pérez Ávila, Julián

Portes, José

Taure, Francisco
Primera actriz

Escenografía: Bulbena, Carratalá, Colmenero y Mignoni.

B) Repertorio de obras interpretadas:

El amante de Madame Vidal. ¡La Condesa está triste! Doña Hormiga. Los duendes de Sevilla. Ecos de sociedad. La gata de angora.

Compañía de Comedias de Barrón-Galache (26-3-32 a 3-4-32)

\section{A) Componentes:}

Ajenjo, Conchita

Alcalde, María

Arcal, Manuel

Barrón, Isabel

Primera actriz

Galache, Ricardo

Primer actor y director

Guerrero, Luis G.

Lamas, Josefina

Mas, Herminia

Portes, José

Taure, sr.

Vico, Gonzalo.

B) Repertorio de obras interpretadas:

La diosa rie. Fuente escondida. Las llamas del convento. La noche loca. El peligro rosa. Solera. Todo Madrid lo sabía. 
Compañía de Comedias de Barrón-Galache (8-9-33 a 14-9-33)

A) Componentes:

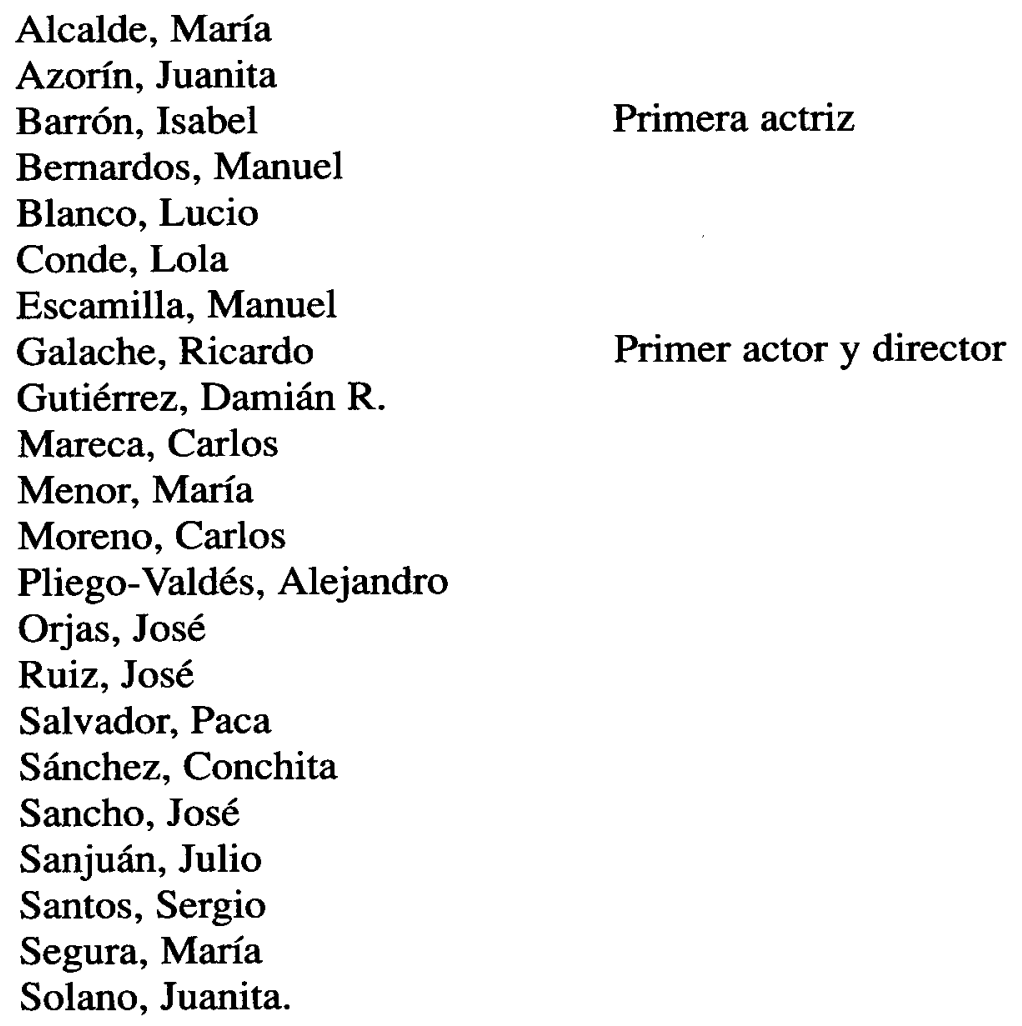

B) Repertorio de obras interpretadas:

Anacleto se divorcia. La flor de los guisantes. La gobernadora. El refugio. Sol y sombra. ¡Te quiero, Pepe! La virtud sospechosa.

Compañía de Comedias de Barrón-Galache (14-12-33 a 19-12-33)

\section{A) Componentes:}

Barrón, Isabel

Galache, Ricardo.

B) Repertorio de obras interpretadas:

El creso de Burgos. Equilibrios. Juanito Arroyo se casa. La verdad inventada. La voz de su amo. 


\section{Compañía de Comedias de Barrón-Galache}

(3-12-34 a 7-12-34)

\section{A) Componentes:}
Barrón, Isabel
Blázquez, Carmen
Cabeza, Arturo
Cano, Pablo
Carrasco, Concha
Galache, Ricardo
García, José
Gil, Emilia
La Riva, Fernando
Mainar, Ángel
Martín, Obdulia
Mas, Irene
Montalbán, Julia
Moreno, Teodora
Novajas, Modesto
Puyol, Joaquín
Quirós, Francisco de
Ramos, Concha
Robles, Francisco

Primera actriz

Apuntador

Decorados: Fontanals, Colmenero, Castels, Giovanini y Soler Gerente: Gómez Ferrer, Francisco

Maquinista: Cardoso, Ángel

Regidor de escena: Granja, Ricardo.

\section{B) Repertorio de obras interpretadas:}

Cinco lobitos. Cuentan de una mujer. La eme. Memorias de un madrileño. El padre soltero.

\section{C) Otras obras del repertorio:}

Como tú, ninguna. Fuente escondida. Hombre de presa. Juanito Arroyo se casa. Madrileña bonita. No más lobos. Raffles. La sirena varada. Tú el barco, yo el navegante. La verdad inventada. Vida y leyenda de Caperucita Encarnada. La virtud sospechosa. 
3.5. Compañía Dramática de Margarita Xirgu (11-10-24 a 22-10-24)

\section{A) Componentes:}

Agudín, Luis P.

Alcaide, Luis

Alicar, Milagros

Arrate, Carmen

Burgos, Joaquín

Carbonell, Carmen

Fernández de Córdoba, Fernando

Gorostegui, Rosa Luisa

Iniesta, Julio

Kayser, Lolita S.

López Silvia, Francisco

Marín de Castro, Salvador

Millanes, María

Muñoz, Alfonso

Primer actor

Muñoz, Amelia

Ortín, Miguel

Pacelo, Julia

Ruste, José

Sánchez París, Rafael

Siria, Ana de

Xirgu, Margarita

Primera actriz y directora.

B) Repertorio de obras interpretadas:

Carmen. La casa en orden. Cristalina. La dama de las camelias. L'aigrette. Mariana. Marianela. La mujer desnuda. La niña de Gómez Arias. La pecadora. Rosas de otoño.

C) Otras obras del repertorio:

Magda. La mala ley. El mal que nos hacen. Primerose.

Compañía Dramática de Margarita Xirgu (9-2-29 a 14-2-29)

\section{A) Componentes:}

Carbonell, Carmen

Fresno, Fernando 
Gallego, Julio

García, José

García Alonso, Aurora

Illescas, Eugenia M.

Larra, María

López Silva, Francisco

Marín de Castro, Salvador

Mesa, Pascuala

Muñoz, Alfonso

Primer actor

Muñoz, Pilar

Ortín, Miguel

Pacelo, Julia

Peña, Luis

Porredón, Fernando

Porredón, Luis

Sanjuán, Elías

Xirgu, Margarita

Primera actriz y directora.

B) Repertorio de obras interpretadas:

Barro pecador. Cristalina. La ermita, la fuente y el río. El estudiante de Vich. Más fuerte que el amor. ¡No quiero, no quiero! Pepita Jiménez.

C) Otras obras del repertorio:

Fedora. La mariposa que voló sobre el mar. La noche iluminada. Novelera. La reina del mundo.

Compañía Dramática de Margarita Xirgu (21-2-30 a 24-2-30)

\section{A) Componentes:}
Alcaide, Luis
Cañizares, José
Cobeña, Benito
Echaide, Luis
García, José
Gómez, Manuel
Illescas, Eugenia M.
López Sevilla, Encarnación
Maximino, Alejandro 
Mesa, Pascuala

Muñoz, Alfonso

Muñoz, Mimí

Muñoz, Pilar

Ortín, Miguel

Pacelo, Julia

Peña, Luis

Peña Illescas, Luis

Peña Illescas, Pastora

Porredón, Fernando

Santaularia, Josefina

Vigo, Eloísa

Xirgu, Margarita.

Decorado y atrezzo, propiedad de la empresa. Diseño de decorados para Mariana Pineda: Dalí, Salvador.

B) Repertorio de obras interpretadas:

Campo de armiño. Los fracasados. Mariana Pineda. Rosas de otoño. Santa Juana.

Compañía Dramática de Xirgu-Borrás (26-10-34 a 28-10-34)

A) Componentes:

Aguirre, Fernando

Álvarez Diosdado, Enrique

Arias, María

Borrás, Enrique

Primer actor y director

Cañizares, José

Collado, Carmen

Contreras, Alberto

García, Olimpia

García Álvarez, Enrique

Guitart, Enrique

López Lagar, Pedro

Merino, Ricardo

Muñoz, Pilar

Nalda, Amanda

Ortín, Miguel 
Porredón, Fernando

Pradas, Isabel

Rivas Cherif, Cipriano de

Asesor literario y artístico

Ruiz Paris, Rosario

Sánchez Ariño, Amalia

Vigo, Eloísa

Xirgu, Margarita

Primera actriz.

B) Repertorio de obras interpretadas:

El alcalde de Zalamea. Ni al amor ni al mar. La noche del sábado. Tierra baja.

C) Otras obras del repertorio:

El abuelo. La Cenicienta. El Gran Galeoto. La loca de la casa. La sirena varada.

3.6. Compañía de Comedias de María Gámez (13-2-26 a 25-2-26)

\section{A) Componentes:}

Aranaz, sra.

Arbó, sr.

Arenas, sr.

Ferrer, Juana

Actriz cómica

Gámez, María

Primera actriz y directora

Hernández, Patrocinio

Larrea, Margarita

Maximino, Alejandro

Muñiz, Juan

Tejada, sr.

B) Repertorio de obras interpretadas:

El amigo Teddy. El ardid. La boda de Quinita Flores. La casa de salud. El chanchullo. Doña Diabla. El juramento de la Primorosa. Lecciones de buen amor. Lo que tú quieras. Malvaloca. Margarita la Tanagra. María Victoria. La pluma verde. El secreto de Lucrecia. 
Compañía de Comedias de María Gámez (23-12-26 a 9-1-27)

A) Componentes:

Albaladejo, Amalia

Arenas, Miguel

Gámez, José

Gámez, María

Directora y primera actriz

Gámez C., Luisa

Gay, María Teresa

González, José

Apuntador

Guerra, Manuel

Hernández, Patrocinio

Izuel, Heraclio

Leygualda, Ricardo

Apuntador

Lizalde, José Luis

Pardo, Aurelio

Paris, Dolores

Plana, Ángela

Pozanco, Miguel

Servet, Mercedes

Sierra de Luna, José

Soto, Concepción

Torner, Antonio

Trujillo, Manuel

Valls, José

Apuntador

Representante: Gómez Uzal, Luis.

B) Repertorio de obras interpretadas:

Alfonso XII, 13. Aventura. La boda de Quinita Flores. La casa de salud. Una comedia para casadas. Charlestón. La chocolaterita. Su desconsolada esposa. Doña Diabla. Doña Tufitos. Un drama de Calderón. El espanto de Toledo. La familia es un estorbo. La gloria de los humildes. Margarita la Tanagra. No basta ser madre. Rocío, la canastera o Entre calé y calé. Tenorio musical.

C) Otras obras del repertorio:

La aventura del coche. Mamá es así. La novela de Rosario. La novela de Rose-Mary. Pancho Robles. Que no lo sepa Fernanda. Las superhembras. Voy a ser cocota. 
Compañía de Comedias de María Gámez (18-2-28 a 27-2-28)

\section{A) Componentes:}

Alcalde, María

Galache, Ricardo

Gámez, María

Primera actriz

González, Eusebio

Guerra, Manuel

Hernández, Patrocinio

López de Rueda, José Luis

Melgarejo, María

Ortega, Cristina

Porredón, Fernando.

B) Repertorio de obras interpretadas:

Una comedia para casadas. La ermita, la fuente y el río. La jaula de la leona. Mi mujer es un gran hombre. Los mosquitos. El secreto de Lucrecia. El señor Adrián el primo. Tambor y cascabel.

\subsection{Compañía de Revistas del Teatro Ruzafa de Valencia} (9-9-32 a 15-9-32)

\section{A) Componentes:}
Abad, Carmen
Abad, Dora
Albalat, Pepita
Alcácer, Pepita
Alós, Manuel
Allustante, María
Andrés, Fernando
Calvo, Rosario
Cruz, Pedro
Cubero, Carmen
Egea, Cándida
Estela, Roberto
Fontana, Rosita

Vicetiple

Vicetiple

Vicetiple

Actriz

Actor

Vicetiple

Actor

Vicetiple

Actor

Actriz

Vicetiple

Maestro concertador

Actriz 
Fornés, Fernando

Friné, Amparo

Furtó, Encarnita

Garain, Ángel

Gil, Leopoldo

Gómez, Eduardo

Gómez, José

Gómez Bur, Vicente

Gómez Rosell, Francisco

Hidalgo, Maruja

Izquierdo, Paquita

Izquierdo, Purita

Jimeno, Consuelo

León, Ignacio

Leonardo, Conchita G.

López, Leonor

López, Lolita

Martí, Vicenta

Martín, Matilde

Miguel Ángel, Amparo

Monserrat, Conchita

Morant, Lolita

Nadal, Julio

Negra de las Pampas

Pardo, María

Perales, Ana

Pérez, Antonia

Signes, Carmen

Suárez, Blanquita

Tamarit, Pascual

Tamarit, Vicenta

Tierra, Vicente

Tomás, Amelia

Tomás, Araceli

Tomás, Miguel

Tormo, Patricio

Vidal, Conchita
Actor

Actriz

Vicetiple

Actor

Director

Actor

Actor

Actor

Primer actor cómico

Actriz

Actriz

Vicetiple

Vicetiple

Primer actor cómico

Actriz

Vicetiple

Vicetiple

Actriz

Vicetiple

Actriz

Vicetiple

Actriz

Actor

Bailarina

Vicetiple

Vicetiple

Vicetiple

Vicetiple

Actriz

Actor

Vicetiple

Actor

Vicetiple

Actriz

Maestro de baile

Actor

Vicetiple

Escenografía (quince decorados): Asensi, Morales y Peris

Vestuario (150 trajes): Capistrós, Manolita y Hurtado, Carmen. 
B) Repertorio de obras interpretadas:

La bomba. La guita. Las Leandras. El país de los tontos.

C) Otras obras del repertorio:

Campanas al vuelo. La niña de la Mancha. El país de la revista. Las pavas. Pele Mele. Las peliculeras.

Compañía de Revistas del Teatro Ruzafa de Valencia (9-9-33 a 16-9-33)

\section{A) Componentes:}

Bernal, sr.

Bilbao, Julia

Cruz, sr.

Frey, Anny

Bailarina

Gómez Bur, sr.

Gómez Rosell, Francisco Actor

Hidalgo, María

León, Ignacio

Primer actor

Máñez, Paquita

Ruiz, Vicenta

Suárez, Blanquita

Primera vedette.

B) Repertorio de obras interpretadas:

Las faldas. Las Leandras. Mi costilla es un hueso. La pipa de oro ¿Qué pasa en Cádiz?

Compañía de Revistas del Teatro Ruzafa (7-5-36 a 8-5-36)

\section{A/ Componentes:}

Andrés, Fernando

Bellver, Francisco

Caruana, Vicente

Cruz, Pedro

Darling, Guillermina

Escribá, Elena
Actor

Actor

Actor

Actor

Tiple

Bailarina 
Francis

Frontera, Juan

Gil, María

Gómez, José

Grancha, Vicente

Máñez, Encarnita

Martínez, Juanito

Páez, Angelita

Páez, Conchita

Panadés, Eliseo

Peidró, Eugenio

Peris, Alfonso

Pesseto, María

Silvestre, María

Tena, Luis

Tomás, Amelia

Tomás, Araceli

Ventura, Rigoberto
Bailarín

Actor

Tiple lírica

Maestro director

Actor

Tiple cómica

Primer actor y director

Tiple

Primera vedette

Actor

Tenor cómico

Apuntador

Tiple

Característica

Apuntador

Tiple

Vedette

Maestro director

Catorce vicetiples

Decorados: Asensi y Morales, Díaz Peris

Gerente: Colás, Alfredo

Jefe atrezzo: Sánchez, José

Jefe maquinaria: López, Adolfo

Sastrería-moda: Capistrós y Viuda de Camps

Decorados, sastrería y atrezzo: propiedad del Teatro Ruzafa de Valencia.

B) Repertorio de obras interpretadas:

La de armas tomar. Mujeres de fuego.

3.8. Compañía de Comedias del Teatro Lara (4-11-24 a 9-11-24)

A) Componentes:
Alba, Leocadia
Primera actriz
Balaguer, José
Benítez, Juan
Cañete, María 
Catalá, Concha

Córdoba, Gonzalo de

Isbert, José

Méndez, Elisa

Méndez, Lola

Ortolano, sr.

Simó Raso, Ricardo

Primer actor y director

Soler Marí, Salvador.

B) Repertorio de obras interpretadas:

Currito de la Cruz. La escondida senda. Frente a la vida. Hijo de mi alma. La mala ley. Marido modelo. El mundo es un pañuelo. Por las nubes.

Compañía de Teatro Lara (11-6-26 a 16-6-26)

\section{A) Componentes:}

Alba, Leocadia

Primera actriz

Amyach, Enrique

Armisen, Matilde

Balaguer, José

Benítez, Juan

Catalá, Concha

Córdoba, Gonzalo de

Cuevas, Carmen

Gelabert, Hortensia

Gonzálvez, sr.

Isbert, José

Málaga, Mercedes

Martínez, Raquel

Méndez, Elisa

Rivas, María de las

Rodríguez Alenza, P.

Soler Marí, Salvador

Thuillier, Emilio

Primer actor y director. 
B) Repertorio de obras interpretadas:

Alfilerazos. Cobardías. El chanchullo. La Galana. El infierno de aquí. El marido de la estrella. Mister Beverly.

Compañía de Comedias del Teatro Lara (8-9-29 a 17-9-29)

A) Componentes:
Alba, Leocadia
Alenza, Jacinta
Caballero, Carmen
Camarero, Asunción
Camarero, Ramón
Campos, Gaspar
Carbonell, Carmen
Catalá, Concha
Córdoba, Gonzalo de
Domínguez, Soledad
Esparza, María del Carmen
Galiana, Matilde
González, José
González, Manuel
Martín Gómez, Pilar
Noriega, Amelia
Rodríguez, Nicolás
Samsó, Roberto
Torner, Antonio
Ulloa, Luis
Vico, Antonio.

Director y primer actor

B) Repertorio de obras interpretadas:

El amor que pasa. Cobardías. El conflicto de Mercedes. Doña Clarines. La Galana. Ganas de reñir. Lo que tú quieras. Marido modelo. Puebla de las mujeres. Raquel. Rosas de otoño.

\section{C) Otras obras del repertorio:}

A martillazos. Acacia y Melitón. Alfilerazos. Al natural. Concha la limpia. Cuarenta años después. Los chorros del oro. La fuerza del mal. La mala ley. El mundo es un pañuelo. El náufrago. Por las nubes. 


\subsection{Cuadro Artístico de las Misiones Pedagógicas (18-5-33)}

\section{A) Componentes:}

No se especifican.

B) Obras interpretadas:

El paso de las aceitunas.

\subsection{Compañía de Teatro Universitario «La Barraca» (4-7-33)}

\section{A) Componentes:}

García Lorca, Federico

Ugarte, Eduardo

B) Obras interpretadas:

Fuenteovejuna.
Director

Director.

\section{Referencias bibliográficas}

FUSTER, Francisco (1974). Historia del teatro en Albacete, Edición del autor. Albacete: Gráficas Fuentes.

García TeMPLADo, José (1974). Albacete. León: Everest.

- (1980). El teatro anterior a 1939. Madrid: Cincel.

MATEOS ARCÁNGEL, Alberto (1983). Evocaciones y recuerdos albaceteños. Albacete: Diputación de Albacete.

OCHANDO MADRIGAL, Emilia (2000). El teatro en Albacete durante la Edad de Plata. Albacete: Instituto de Estudios Albacetenses (prólogo de José Romera Castillo).

Oliva, César, Editor (1984). Ensayos sobre teatro español de los años 20. Murcia: Cuadernos de la Cátedra de Teatro de la Universidad de Murcia.

Povedano Arizmendi, Enrique (1930). Cómicos al desnudo. Madrid: s. e.

Rey Faraldos, Gloria (1992). «El teatro de las Misiones Pedagógicas». En El teatro en España. Entre la tradición y la vanguardia (1918-1939). Dru 
Dougherty y M. Francisca Vilches (eds.), 153-164, Madrid: Tabapress. Rodrigo, Antonina (1988). Margarita Xirgu. Madrid: Aguilar.

RuzZ Ramón, Francisco (1986). Historia del teatro español. Siglo XX. Madrid: Cátedra.

SÁENZ dE la CAlZAdA, Luis (1976). «La Barraca» Teatro Universitario. Madrid: Biblioteca de la Revista de Occidente. 